\title{
O DESENVOLVIMENTO DE ATIVIDADES PRÁTICAS NA ESCOLA: UM DESAFIO PARA OS PROFESSORES DE CIÊNCIAS
}

\author{
Practical activities development: \\ a challenge to science teachers
}

\author{
Marcelo Leandro Feitosa de Andrade ${ }^{1}$ \\ Vânia Galindo Massabni ${ }^{2}$
}

\begin{abstract}
Resumo: As atividades práticas contribuem para o interesse e a aprendizagem em Ciências, especialmente quando investigativas e problematizadoras. Assim, o objetivo foi entender como professores de Ciências do Ensino Fundamental percebem estas atividades, bem como saber se são por eles utilizadas e os motivos para o seu uso/não uso no cotidiano da escola. Para isso, entrevistamos professoras de Ciências, que indicaram raramente utilizar atividades práticas e terem dificuldades nesta utilização. Quando o fazem, é após aulas teóricas, para apenas ilustrar a teoria . Justificam raramente recorrerem a tais atividades pela insegurança, falta de apoio e infraestrutura da escola. As professoras afirmam valorizar as atividades práticas, mas as percebem apenas como complemento para as aulas teóricas. Entendem serem necessárias mais atividades práticas, porém ficam angustiadas por não conseguirem desenvolvê-las nas condições de trabalho. Considerando as dificuldades apontadas, são oferecidas sugestões para se promoverem estas atividades no sistema público de ensino brasileiro.
\end{abstract}

Palavras-chave: Ensino fundamental. Ensino de Ciências. Prática de ensino.

\begin{abstract}
Practical activities contribute to interest and learning in Science, especially when they require investigation and problematization. So, the goal of the study was to understand how Science teachers in Fundamental Education perceive these activities and also to know if there are applied and the reasons for their use/not use in everyday schooling. The study interviewed Science teachers, who had indicated difficulties and who used practical activities rarely. When they are used, it happens after theoretical study, to illustrate theory only. Teachers justify rarely using these practices because they feel insecure and they do not have school structure and human support. Teachers value practical activities but perceive practical activities only as complementary to theoretical classes. Teachers understand the necessity for more practical activities, but feel anguish because they do not make it happen. The researchers considered difficulties expressed by teachers and give some suggestions to encourage practical activities in Brazilian educational public system.
\end{abstract}

Keywords: Science education. Teacher practice.

${ }^{1}$ Graduação em Ciências Biológicas, mestre em Ciências (Biologia na Agricultura e no Ambiente). Analista Ambiental, Instituto Chico Mendes. Piracicaba, SP, Brasil. <mfeitosa@usp.br>

${ }^{2}$ Graduação em Ciências Biológicas, mestre em Ensino de Ciências, doutora em Educação Escolar. Docente, Departamento de Economia, Administração e Sociologia, Escola Superior de Agricultura "Luiz de Queiroz", Universidade de São Paulo (ESALQ/USP). Piracicaba, SP, Brasil. <massabni@esalq.usp.br>

${ }^{1}$ Rua Serra Dourada, 896

Jardim São Fernando - Campinas, SP

13.100-325 
Andrade, M. L. F.; Massabni, V. G.

\section{As atividades práticas no Ensino de Ciências}

Estudo do meio, experimentação, visita com observações, entre outras, são exemplos do que podemos chamar de atividades práticas, fundamentais para o ensino de Ciências. A possibilidade de que estas atividades estejam praticamente ausentes no cotidiano da escola é preocupante, em especial quando ocorre nos primeiros contatos com a Ciência, no Ensino Fundamental. Este é um momento crucial para fundamentar a construção de uma visão científica, com sua forma de entender e explicar as leis, fatos e fenômenos da natureza, bem como as implicações socioambientais deste conhecimento.

Assim, os objetivos deste estudo foram: entender como os professores de $5^{\mathrm{a}}$ a $8^{\mathrm{a}}$ séries $\left(6^{\circ}\right.$ ao $9^{\circ}$ ano) de duas cidades do interior de São Paulo percebem a importância das atividades práticas; saber se utilizam tais atividades em seu cotidiano, e compreender as razões para o seu uso ou não-uso nas aulas de Ciências.

As atividades práticas são uma forma de trabalho do professor, e querer utilizá-las, ou não, é uma decisão pedagógica que não depende apenas da boa vontade do docente, seu preparo ou condições dadas pela escola. Os professores, ao decidirem como desenvolver suas aulas, realizam julgamentos pessoais sobre como devem agir, avaliando crenças, valores e conhecimentos adquiridos na formação e no exercício profissional. Se o professor valoriza as atividades práticas e acredita que elas são determinantes para a aprendizagem de Ciências, possivelmente buscará meios de desenvolvê-las na escola e de superar eventuais obstáculos. As atividades práticas permitem aprendizagens que a aula teórica, apenas, não permite, sendo compromisso do professor, e também da escola, dar esta oportunidade para a formação do aluno. Nem sempre os professores tomam estas decisões de forma consciente, podendo ser levados a repetir a forma de ensino que vivenciaram quando alunos ou desenvolvida por outros professores. O modo de agir dos professores se deve à aprendizagem de modos de ação tradicionalmente aceitos e realizados por seus pares na socialização da profissão, em grande parte realizada na própria escola (TARDIF, 2002). Os professores, ao deixarem de utilizar atividades práticas, podem estar incorporando formas de ação presentes historicamente no ensino, pautado pela abordagem tradicional, sem maiores reflexões sobre a importância da prática na aprendizagem das Ciências.

A preocupação com a falta de tais atividades nas escolas não é recente. As atividades práticas, em especial as experimentais, foram o cerne das propostas curriculares americanas divulgadas na década de 1950, as quais viriam influenciar, também, o Brasil nas décadas de 1960 e 1970, por meio das ações do Instituto Brasileiro de Educação, Ciência e Cultura IBECC (KRASILCHIK, 1987; 2004). À época, rompeu-se um longo período de estabilidade nos currículos de Ciências, rompimento esse influenciado pelo cenário internacional de industrialização e o desenvolvimento tecnológico e científico pós Segunda Guerra Mundial, que teve, como marco inicial, o lançamento do satélite soviético Sputnik, em 1957 (ERN; AIRES, 2007). O movimento de mudança curricular iniciado visava, prioritariamente, despertar jovens para a formação de novos quadros de cientistas (OLIVEIRA, 1991), dando condições de os países participarem da nova configuração mundial. Estes projetos se caracterizavam por ver a escola e a sala de aula como espaços onde se produz (faz) Ciência, e as atividades práticas eram compreendidas como viabilizadoras da aprendizagem por redescoberta, em que, pela indução, se supunha que o aluno chegaria ao conhecimento científico. O objetivo era facilitar a apren- 
dizagem e aumentar o interesse por Ciência, concebendo os alunos como pequenos cientistas. O ideal deste movimento não foi plenamente alcançado por diversas razões (OLIVEIRA, 1991), uma das quais é a diferença entre o acervo teórico-metodológico dos cientistas e o dos estudantes, que limitava ou impedia conclusões semelhantes entre ambos.

Atualmente, um projeto originalmente americano, lançado na França, em 1996, com o nome de "La main à la patê", foi divulgado no Brasil, em 2001, como "ABC na educação científica - mão na massa”. É um projeto que valoriza as atividades práticas experimentais, realçando a comunicação de ideias e as interações discursivas durante a atividade (ZANON; FREITAS, 2007). Segundo Coquidé (2008), este projeto propõe um procedimento pedagógico centrado sobre a exploração e experimentação de objetos e/ou fenômenos, em uma ótica construtivista. Os alunos realizam as experiências e as discutem com o objetivo de compreenderem a teoria por elas contemplada.

O uso de atividades experimentais propostas como problemas a serem resolvidos é outro enfoque divulgado nas pesquisas em Ensino de Ciências que requer atividades práticas. Nesta perspectiva, o professor pode propor problemas na forma de pequenos experimentos a fim de permitir aos alunos realizarem um conjunto de observações, tarefas de classificações, entre outras, cabendo, ao docente, um papel de orientador da aprendizagem (CAMPANÁRIO; MOYA, 1999). Percebe-se, então, que as atividades práticas devem estar situadas em um contexto de ensino e aprendizagem em que se desenvolvem tarefas de compreensão, interpretação e reflexão. Quando em um ensino menos diretivo, as atividades práticas podem envolver os alunos em todas as fases, até no planejamento experimental, tendo um caráter investigativo ao incentivar a elaboração e criação de hipóteses, de estratégias e de soluções para problemas. Esta forma de utilizar e compreender as atividades práticas questiona o uso da prática descontextualizada e reprodutiva, tornando-se momento de aprendizagem repleto de raciocínio e criação.

No Brasil, as atividades práticas são consideradas uma forma de favorecer a consecução dos objetivos propostos pelos Parâmetros Curriculares Nacionais (PCN) para o ensino de Ciências. Os PCN de Ciências Naturais indicam que são procedimentos fundamentais para o ensino da área aqueles que permitem a investigação, a comunicação e o debate de fatos e ideias, possibilitados pela observação, experimentação, comparação, estabelecimento de relações entre fatos ou fenômenos. Do mesmo modo, os PCN valorizam atitudes que, na ótica do presente estudo, podem ser trabalhadas nas atividades práticas, como: o incentivo à curiosidade, o respeito à diversidade de opiniões, a persistência na busca de informações e de provas obtidas por meio de investigação (BRASIL, 2000). A observação e a experimentação são indicadas pelos PCN como estratégias didáticas que auxiliam na obtenção de informação, as quais devem contemplar fontes variadas, como a leitura de textos informativos e projetos desenvolvidos preferencialmente em um contexto de problematização.

Portanto, as possibilidades de aprendizagem proporcionadas pelas atividades práticas dependem de como estas são propostas e desenvolvidas com os alunos. Atividades práticas que investiguem e questionem as ideias prévias dos educandos sobre determinados conceitos científicos podem favorecer a mudança conceitual, contribuindo para a construção de conceitos, embora este processo de mudança nem sempre ocorra no sujeito e existam diferentes acepções sobre a gênese e desenvolvimento conceitual. Além disto, a compreensão de um só conceito não dá conta de explicar a complexidade e riqueza de fenômenos naturais estudados, e a prática permite explorar outros conceitos envolvidos no fenômeno, assim como relacionar 
Andrade, M. L. F.; Massabni, V. G.

áreas do conhecimento, promovendo a interdisciplinaridade. Dependendo de sua condução, as atividades práticas podem favorecer, entre os estudantes, modos de pensar, atitudes e até interconexões entre Ciência, tecnologia, ambiente e sociedade. Assim, tais atividades podem aproximar o ensino à Ciência, que costuma ser apresentada em uma visão deformada nas aulas (CACHAPUZ et al., 2005). Auxiliar o aluno a entender a atividade científica enquanto atividade humana investigativa do mundo natural, entremeada pelos aspectos psicossociais e paradigmáticos desta investigação, como indicado por Kuhn (1979), não é um propósito possível enquanto as aulas se absterem de criar um contexto em que a prática seja vista como parte dos caminhos que a Ciência trilha para progredir. Além disso, atividades práticas possivelmente incentivam o gosto pela área, sendo comum a satisfação dos estudantes em participarem delas.

Estudos em Ensino de Ciências advogam que as atividades práticas sejam concebidas de acordo com a ideia de que o aluno é o construtor de seu próprio conhecimento, necessitando buscar, reformular e refletir para reestruturar seus conhecimentos, com o auxílio do professor e de colegas. Um destes estudos é o de Demczuk, Amorim e Rosa (2005), e se refere à necessidade de envolvimento do aluno com a atividade proposta, para que o conhecimento possa ser construído, a partir de atuações concretas. Souza et al. (2005), por sua vez, concordam que as aulas de laboratório possibilitam, ao aluno, construir conhecimentos e realizar a mudança conceitual.

Neste sentido, as atividades práticas do tipo investigativo têm grandes possibilidades de promover esta construção, seja porque os estudantes interagem com o fenômeno, revendo seus conceitos anteriores, seja porque a interpretação da prática requer a construção de novos conhecimentos e reorganização dos anteriores na tentativa de dar sentido ao que ocorre, havendo um processo construtivo. Quando requerem do aluno uma postura investigativa, as atividades práticas levam os alunos ao envolvimento com os fenômenos, porque podem fazer conjecturas, experimentar, errar, interagir com colegas e expor seus pontos de vista para testar a pertinência e validade das conclusões a que chegam durante tais atividades (ZANON; FREITAS, 2007). Assim, atividades práticas investigativas conseguem integrar a parte experimental aos aspectos teóricos necessários à sua compreensão (ROSITO, 2003).

Por sua vez, atividades práticas que pressupõem apenas ilustrar a teoria são entendidas como limitadas quanto ao seu potencial de auxílio à aprendizagem, pois geralmente se realizam nos mesmos moldes do ensino tradicional, sem espaço para o aluno manifestar e redimensionar seus conhecimentos. Esta forma de desenvolvimento das atividades está muito presente nas aulas, como observado por Alvarez (2002) ao estudar aulas práticas da disciplina de Bioquímica no Ensino Superior. Em sua pesquisa, nota que estas aulas exerciam funções que não iam muito além da aula teórica em termos de conteúdos, treinamento técnico e campo conceitual. Segundo Krasilchik (2004), a chance de a aula prática incentivar a criatividade do aluno muitas vezes é perdida quando a aula é organizada de modo que o aluno siga instruções detalhadas para encontrar as respostas certas, e não para resolver problemas, reduzindo o trabalho de laboratório a uma simples atividade manual.

Um outro exemplo de que as atividades práticas estão aquém de seu potencial é dado por Coquidé (2008). Em sua pesquisa, ela analisou roteiros de trabalhos práticos de Física da França e percebeu que $90 \%$ dos 55 roteiros analisados exigiam relações entre grandezas, mas apenas $10 \%$ envolviam o estudante na previsão ou escolha, dentre as várias explicações, da mais plausível. De acordo com esta autora, a visão dos professores sobre os trabalhos práticos 
deixa subentendido que, para eles, é suficiente "fazer para compreender" e "ver para provar", acreditando que o aluno aprenderia apenas ao fazer o experimento, ou ao ver, na prática, as "provas" das explicações teóricas, sem maiores reflexões. Nestas aulas, também, há permanência de certas experiências prototípicas, presentes nos livros didáticos, e que funcionam como ritos. Segundo ela, cabe repensar as formas e funções das atividades experimentais no ensino.

Até o momento, no presente artigo, apresentamos alguns estudos sobre atividades práticas (por exemplo, os de ALVAREZ, 2002; ZANON; FREITAS, 2007; DEMCZUK; AMORIM; ROSA, 2005). Estes estudos, entre outros citados nas referências bibliográficas do artigo aqui apresentado, referem-se a "atividades experimentais", "experimentação", "aulas de laboratório" e/ou "aulas práticas", que são modalidades de atividades práticas. O leitor pode perceber que nem sempre os autores utilizam a expressão "atividades práticas" para descreverem com o que trabalharam. Percebemos esta diversidade de expressões ao realizarmos um levantamento bibliográfico inicial para a presente pesquisa e, embora nosso levantamento não tenha tido o porte de uma revisão bibliográfica, chama a atenção terem sido apenas três os estudos encontrados (HODSON, 1994, apud ROSITO, 2003; RABONI, 2002; BARRETO FILHO, 2001) que se referiam às "atividades práticas" utilizando esta expressão. Chama a atenção também a referência destes três estudos às atividades práticas como formas de ensinar que não exigem contato ou experiência concreta sobre os fenômenos. Hodson (1994 apud ROSITO, 2003), entende que atividades práticas são qualquer trabalho em que os alunos estejam ativos e não passivos, o que inclui a interpretação de gráficos, por exemplo, sem necessário envolvimento do estudante na obtenção dos dados do gráfico. Raboni (2002), em seu estudo com professoras dos anos iniciais do Ensino Fundamental, também utiliza a expressão "atividades práticas", incluindo, entre elas, a leitura e a interpretação de quadrinhos. O autor buscava compreender os processos de elaboração do conhecimento sobre tais atividades pelas professoras, realizando encontros nos quais propunha e discutia algumas atividades práticas. Do mesmo modo, Barreto Filho (2001) considera atividades práticas como:

[...] modalidades de procedimento que objetivam conseguir informações, como nos casos da observação ambiental, observação laboratorial, da leitura, da escrita, do dialogar com colegas e professor, e ainda, desenvolvidas de forma que se complementem e possam contribuir com o aluno, no sentido de chegar a internalização do conhecimento formal. (BARRETO FILHO, 2001, p. 1, grifo nosso)

Cabe tudo como atividade prática, no sentido empregado por estes três estudos. Qualquer atividade escolar realizada pelo aluno seria uma atividade prática. A atividade prática, nesta acepção, não teria suas especificidades, bastando que se envolvesse ativamente o aluno em alguma tarefa escolar, seja ela apenas intelectual ou não. Uma atividade intelectual, no entender do presente estudo, não deve ser vista como atividade prática, pois prescinde da obtenção e manipulação de dados obtidos da natureza. A atividade prática, em si, requer envolver ativamente o aluno, mas este envolvimento não basta para defini-la. Do mesmo modo, entende-se que as aulas práticas e/ou experimentais são uma forma de atividade prática, mas não podem ser entendidas como as únicas. 
Andrade, M. L. F.; Massabni, V. G.

Krasilchik (2004) se refere às aulas práticas como aquelas que permitem aos alunos ter contato direto com os fenômenos, manipulando os materiais e equipamentos e observando organismos, em geral envolvendo a experimentação. Ou seja, estas aulas possuem atividade prática. Para Krasilchik (2004), as demonstrações não são tidas como aulas práticas, uma vez que é o professor que demonstra, mesmo que exista algo concreto para o aluno. Segundo ela, demonstrações, excursões e aulas práticas pertencem a diferentes modalidades didáticas, sendo que aulas práticas requerem a participação do aluno com seu envolvimento direto na obtenção de dados.

No presente estudo, sentiu-se falta de uma definição mais específica e coerente com o que entendemos por atividades práticas no ensino de Ciências, de forma que divergimos das definições apresentadas nesta introdução. Optou-se aqui por definir atividades práticas como aquelas tarefas educativas que requerem do estudante a experiência direta com o material presente fisicamente, com o fenômeno el ou com dados brutos obtidos do mundo natural ou social. Nesta experiência, a ação do aluno deve ocorrer - por meio da experiência física - , seja desenvolvendo a tarefa manualmente, seja observando o professor em uma demonstração, desde que, na tarefa, se apresente o objeto materialmente.

Nesta definição, a experiência física com o objeto presente materialmente, explorada na teoria de Piaget (1978 e 1972), é tomada como fundamental para definir se a atividade é prática ou não. Com base na teoria piagetiana, o objeto concreto pode estar presente física ou mentalmente. O objeto concreto deve estar presente fisicamente para que se possa agir sobre ele em uma atividade prática e/ou para que se possa elaborá-lo mentalmente a partir das características observadas. Por meio da experiência física - realizada pelo aluno, quando manipula e testa o objeto, ou realizada pelo professor, no caso de uma demonstração - se retiram dados e se tecem conclusões sobre o mundo natural - que Piaget (PIAGET, 1995) chama de abstração empírica. Estas considerações podem se dar com o objeto presente ou "lembrando-se" dele (a experiência física pode se dar mentalmente). Mas, sendo necessário conhecer o objeto e tendo por pressuposto que o conhecimento desejável pelo professor será aquele conhecimento advindo de um conhecer das propriedades, é factível que a experiência física da atividade prática se refira àquela realizada com o objeto presente fisicamente, e não - apenas - mentalmente. Assim, na atividade prática, a experiência física deve necessariamente ocorrer para que o estudante tenha possibilidade de abstrair informações do objeto ou fenômeno estudado, sejam elas confirmações de informações anteriores ou novas informações que a experiência propicia. A experimentação mental pode ocorrer no sujeito mas não define a atividade como prática. Isto porque não seria uma experimentação ocorrida na prática. A manipulação pura e simples de dados em uma atividade prática não contempla a abstração - nem empírica, nem lógico-matemática. Este último tipo de abstração pode decorrer das experimentações que fazemos mentalmente ao avaliarmos as reações dos objetos às nossas ações materiais.

Se não houver envolvimento do estudante - isto é, ações mentais, realizando abstrações - a atividade prática pode tornar-se limitada, restringindo-se à manipulação, sem que ocorra nem mesmo a abstração física.

As considerações a seguir podem ajudar a esclarecer a base teórica piagetiana da definição aqui adotada. Segundo Massabni (2005), derrubar repetidas vezes um objeto nos permite saber sobre ele, se rola, quebra ou flutua; estes são exemplos de ações físicas, em que exploramos as propriedades dos objetos. A experiência física consiste em agir sobre os objetos 
para abstrair conhecimentos a partir dos próprios objetos (PIAGET, 1978), com a presença física ou mental deste objeto. É aquela em que tentamos compreender suas propriedades, aplicando os esquemas que dispomos para que sejam assimiladas, como explicam Coll e Gillièron (1987). O objeto concreto, para Piaget (1972), pode estar presente fisicamente ou interiorizado na mente do sujeito; o objeto não pertence exclusivamente ao mundo material.

Ainda de acordo com Massabni (2005), das experiências com objetos presentes fisicamente, e da própria ação material sobre eles, podem-se abstrair características e propriedades, como seu peso ou cor. Quando nos limitamos a enquadrar o conteúdo da natureza do objeto aos esquemas que possuímos, temos a abstração empírica (PIAGET, 1995). A abstração empírica deve colaborar para a abstração lógico-matemática, quando se retiram conclusões sobre a ação material e se realizam operações mentais com o objeto já presente na mente. A ação lógico-matemática consiste em enriquecer o objeto de propriedades ou relações novas.

Portanto, entende-se aqui que a atividade prática não deve se constituir apenas em atividade mecânica de medição, observação, descrição, entre outras, sem que se extraiam "lições" sobre o objeto estudado. Este objeto pode ser um animal vivo ou conservado, uma planta ou parte dela, um fenômeno físico, como a queda de um objeto, ou reações químicas, ou ainda, o objeto pode ser uma região florestal ou um rio degradado, entre outros. Assim, a atividade prática pressupõe participação do aluno em uma situação de ensino e aprendizagem em que se utiliza ou requer a análise e reflexão sobre dados primários da natureza. A busca destas situações leva o professor a criar tarefas que propiciem, aos estudantes, experiências físicas e lógico-matemáticas, para as quais se faz necessário integrar questões, leituras, debates, que não constituem a atividade prática em si, mas a complementam. A vivência de situações com o objeto fisicamente presente possibilita elaborações teóricas, se esta prática for trabalhada. Por isto, as atividades práticas podem ser desenvolvidas em salas de aula, laboratórios, jardins escolares e em diversos ambientes externos à escola, como parques, jardins públicos, reservas ambientais, museus ou, mesmo, a casa do aluno.

Demonstrações, excursões, experimentos e determinados jogos, desde que permitam experiências diretas com objetos presentes fisicamente, podem, de acordo com a definição proposta pelos autores do presente estudo, ser considerados atividades práticas. Neste sentido, "atividades práticas" não contemplam debate, leitura, aula expositiva e outras de natureza teórica, que colaboram para as aulas com atividade práticas, por exemplo, na sistematização dos conhecimentos observados em uma excursão.

Definir de forma mais precisa "atividades práticas" foi necessário para se analisar se os professores entendem tais atividades em uma das formas apresentadas (apenas como atividades realizadas em aulas experimentais/de laboratório; atividades não exclusivamente experimentais, mas que permitam ao aluno o contato com o objeto presente fisicamente; ou, ainda, atividades desenvolvidas em tarefas escolares que requeiram ação do aluno, quaisquer que sejam elas).

\section{Metodologia do estudo realizado}

Foram entrevistadas 12 professoras de Ciências, sendo cada uma de uma escola de Ensino Fundamental da rede pública estadual paulista, sendo seis de Piracicaba/SP e seis de 
Andrade, M. L. F.; Massabni, V. G.

Campinas/SP. Para a escolha das escolas de Piracicaba, foi considerada a classificação das regiões (Norte, Sul, Leste, Oeste e Centro) pelo Instituto de Pesquisa de Planejamento de Piracicaba - IPPLAP, em 2005. Em cada região, visitou-se uma escola, exceto na região central, em que foram visitadas duas escolas. Já na cidade de Campinas/SP, como a cidade possui duas Diretorias de Ensino, foram escolhidas três escolas administradas pela Diretoria de Ensino Região Campinas Oeste e três escolas administradas pela Diretoria de Ensino Região Campinas Leste, abrangendo, assim, as principais regiões da cidade. A escolha das escolas dentro de cada região foi aleatória.

Nas escolas visitadas era explicado o propósito da pesquisa à direção e, após autorização, pedia-se para a Secretaria ou Direção indicar professores de Ciências a serem convidados a participar da pesquisa. Os professores, ao aceitarem, assinaram um Termo de Livre Consentimento. Cabe indicar que a assinatura deste termo e outros cuidados éticos foram tomados, apesar de o trabalho não contar com um parecer de Comitê de Ética, visto que a instituição em que se realizou a pesquisa não contava, à época, com Comitê de Ética Humana para avaliação da pesquisa. Como eram todas mulheres, foram identificadas como Professora A até $\mathrm{M}$, conforme sequência de agendamento das entrevistas, mantendo-se, desta forma, o anonimato. As entrevistas seguiram um roteiro semiestruturado, sendo integralmente gravadas e transcritas, selecionando-se, posteriormente, as partes aqui reproduzidas. $\mathrm{Na}$ análise, buscou-se identificar tendências gerais nas falas das professoras, a fim de se compreender como pensam e realizam - caso o façam - as atividades práticas.

As questões iniciais destinaram-se a identificar as professoras e, as demais, a esclarecer sobre o significado de aulas e atividades práticas e sobre a utilização/não-utilização de atividades práticas no cotidiano, bem como as razões que sustentam as ações.

$\mathrm{O}$ instrumento utilizado foi o seguinte:

\section{Roteiro para Entrevista Semiestruturada}

\section{Parte 1: Identificação do professor}

1) Qual a sua formação acadêmica? Você cursou Licenciatura? Em qual instituição de ensino?

2) Há quanto tempo se formou? Há quanto tempo você é professor de Ciências?

3) Você atua apenas na rede pública? Em quais outras escolas você trabalha? Tem outra fonte de renda além das aulas?

4) Cite os principais cursos (curso de formação continuada, especialização, mestrado, doutorado etc.) que você realizou/realiza.

\section{Parte 2: Concepção e importância da atividade prática para o professor}

5) Você trabalha ou já trabalhou com atividades práticas em suas aulas de Ciências? Explique porque trabalha /não trabalha com essas atividades em suas aulas de Ciências. 6) Na sua opinião, o que são aulas práticas? Um debate é uma aula prática?

7) Nesta questão, assinale as afirmações de 1 a 6, por ordem de importância (sendo 1 a mais importante e 6 a de menor importância), segundo sua opinião. Quando você usa atividades práticas, se preocupa em (ler opções):

( ) despertar a curiosidade do aluno e motivá-lo. 
O desenvolvimento de atividades práticas na escola: ...

( ) preparar habilidades científicas ( ex: manipulação, observação etc.).

( ) modificar as ideias prévias dos alunos.

( ) desenvolver, no aluno, a capacidade de questionar, refletir, propor hipóteses, interpretar e, desta forma, estimular, no aluno, o raciocínio científico.

( ) facilitar a aprendizagem da Ciência.

( ) comprovar o que foi visto na aula teórica.

( ) Quando você usa atividades práticas em suas aulas de Ciências, você (ler opções):

( ) a utiliza sempre depois da aula teórica

( ) apresenta sempre antes da aula teórica.

( ) sempre tenta apresentar a atividade prática junto com a aula teórica

( ) o momento da atividade prática (antes, durante ou depois da aula teórica) depende do tema/ da escola/da classe em que trabalho.

Explique.

\section{As atividades práticas no cotidiano da escola, segundo as professoras de Ciências}

A entrevista iniciou-se com a identificação das professoras. Das doze professoras entrevistadas, todas possuíam Licenciatura, sendo: quatro em Ciências Físicas e Biológicas (A, C, D e M); seis em Ciências, com habilitação em Matemática (B, E, F, H, I e J); uma (L) em Ciências Biológicas, e uma professora $(\mathrm{G})$ que não informou, única a se graduar em universidade pública. A Professora B lecionava há mais tempo (25 anos), enquanto a Professora $G$ lecionava há menos tempo (três anos). A média de tempo de docência foi de vinte anos. Com exceção da professora $\mathrm{H}$, todas atuavam apenas na escola pública.

Nota-se que as professoras possuem formação adequada para dar aulas de Ciências, no que diz respeito a terem cursado uma Licenciatura. Este dado é importante, pois, se tiveram contato com experimentos em pesquisa ou aulas durante o curso, e se, além disto, foram preparadas pedagogicamente para valorizar e implementar atividades práticas na escola, são maiores as possibilidades de que as realizem. Porém, sabe-se que a formação deficitária dos professores quanto ao conteúdo específico e/ou pedagógico constitui "séria limitação para utilização da experimentação em suas aulas" (ROSITO, 2003, p. 206).

Perguntou-se às 12 professoras se trabalham ou já trabalharam com atividades práticas em suas aulas de Ciências. Cinco professoras (Professoras A, C, E, H e J) afirmaram não trabalhar com atividades práticas e sete (Professoras B, D, F, G, I, L, M) disseram trabalhar ou já ter trabalhado. Porém, estas atividades são raras, como se observa na Tabela 1.

Pela Tabela 1, pode-se perceber que cinco das 12 professoras não utilizam atividades práticas. Porém, mesmo as sete que afirmam utilizar, o fazem raramente, pois são dadas, aproximadamente, três aulas por ano com atividades práticas. Só duas professoras (B e M) consideram utilizar tais atividades mensalmente em seu cotidiano. Era de se esperar maior frequência na utilização de atividades práticas na escola. Isto porque, por um lado, não é de hoje que projetos e anseios de cientistas e pesquisadores na área da educação científica vêm valorizando programas que desenvolvam atividades práticas nas escolas, como indicamos na introdução do presente estudo. Por outro, porque são necessárias ao aprendizado de Ciências, 
Andrade, M. L. F.; Massabni, V. G.

como apresentado por Zanon e Freitas (2007) e pelos PCN (Brasil, 2000). Portanto, há que se indagar os reais impactos destes anseios e orientações na prática de ensino, e buscar formas de ampliar o uso de atividades práticas entre os professores.

Tabela 1. Frequência do uso de atividades práticas pelas professoras entrevistadas.

\begin{tabular}{cccc}
\hline Professora & Não usa atividades práticas & Uso anual ( $n^{\circ}$ vezes) & Uso mensal $\left(n^{\circ}\right.$ vezes) \\
\hline A & $X$ & - & - \\
B & - & $2^{*}$ & $1^{*}$ \\
C & $X$ & - & - \\
D & - & 3 & - \\
E & $X$ & - & - \\
F & - & 4 & - \\
G & - & 3 & - \\
H & $X$ & - & - \\
I & - & 3 & - \\
J & $X$ & - & - \\
L & - & 2 & 1 \\
M & - & - &
\end{tabular}

Fonte: Dados da pesquisa dos próprios autores (ANDRADE, 2007).

"A professora B usa atividades práticas, em média, uma vez por mês, para turmas das $5^{\mathrm{a}}$ e $6^{\mathrm{a}}$ séries, e duas vezes por ano para turmas das $7^{\text {a }}$ e $8^{\text {a }}$ séries.

Quando as atividades práticas são realizadas, buscam-se atividades simples, que não requerem equipamentos sofisticados e nem mesmo um laboratório escolar, como relatos a seguir:

"Já trabalhei com atividades práticas, mas somente experiência simples: a da existência do ar, no Sonrisal eliminando gás carbônico. Já montei maquete." (Professora L)

"Como não temos laboratório, as atividades práticas na nossa escola são fora da sala de aula. Eu sempre escolbo um pedacinho de terra na área da escola e ali en faço um laboratório ao ar livre." (Professora M)

Também foi questionado em que momento as professoras utilizam as atividades práticas durante a disciplina. Foram fornecidas opções de resposta, e uma delas era se recorriam às atividades antes, durante ou depois da aula teórica. As professoras afirmaram utilizá-las depois de os alunos conhecerem a teoria em aula, como dito pela Professora M:

"Sempre depois de uma aula teórica. Raramente dou antes de uma aula teórica. A minha impressão é que me tranqüiliza mais na hora de executar uma atividade, pois eles sabem o que estão fazendo, o que estão executando." (Professora M) 
O desenvolvimento de atividades práticas na escola: ...

A preferência por desenvolver atividades práticas depois da aula teórica está expressa na Tabela 2. Das sete professoras que disseram utilizar atividades práticas, a maioria recorre a tais atividades sempre depois da aula teórica (Tabela 2).

Tabela 2. Momento em que as professoras usam atividades práticas.

\begin{tabular}{cccc}
\hline & \multicolumn{3}{c}{ Momento do uso em relação à aula teórica } \\
\cline { 2 - 4 } Professora entrevistada & Antes & Concomitante/variável & Depois \\
\hline A & - & - & - \\
B & - & - & $X$ \\
C & - & - & - \\
D & - & - & $X$ \\
E & - & - & - \\
F & - & - & $X$ \\
G & - & - & $X$ \\
H & - & - & - \\
I & $X$ & - & $X$ \\
J & - & - & - \\
L & - & $X$ & - \\
M & - & - & $X$ \\
\hline
\end{tabular}

Fonte: Dados da pesquisa dos próprios autores (ANDRADE, 2007).

Utilizar atividades práticas somente ou quase que exclusivamente depois da aula teórica denota a ideia de que são compreendidas como forma de "aplicação" ou "prova" dos conhecimentos aprendidos, atuando como complemento da aula teórica. Este dado corrobora os encontrados por Coquidé (2008), que percebe, pelos roteiros de aulas experimentais, que os professores consideram suficiente mostrar e provar a teoria para que ocorra o aprendizado. Porém, como indicado por Alvarez (2002) em seu estudo, se as aulas práticas se limitam a ilustrar a teoria, ficam aquém de seu potencial, e suas funções são semelhantes às da aula teórica, pouco acrescentando aos estudantes e sem fomentar uma atitude científica. Outra questão, sobre as aulas práticas (que contemplam as atividades práticas), fortaleceu a compreensão de como as professoras pensam. Uma aula prática é entendida pela maioria (7 professoras - B, C, F, I, J, G e L) como aquela em que, especificamente, há um experimento, uma prática laboratorial, desenvolvida exclusivamente no espaço do laboratório escolar: "[...] é uma aula que o aluno manipula materiais do laboratório da escola" (Professora G). "[...] é a desenvolvida no laboratório da escola" (Professora L).

Diferentemente, para outras cinco professoras (A, D, E, H e M), as aulas práticas contemplam estudos práticos nem sempre experimentais ou de laboratório. Elas entendem as aulas práticas como aquelas em que a experiência dos alunos com o que é "palpável” é requerida, de forma coerente com a definição sugerida neste estudo. As afirmações abaixo deixam claro que, para estas professoras, as aulas práticas incluem tarefas educativas que requerem do estudante o envolvimento com a experiência direta. Esta acepção pode ser notada a seguir: 
Andrade, M. L. F.; Massabni, V. G.

"Uma aula prática é a aula que a gente pode levar o aluno para mostrar. Dentro de uma sala de aula, pode ser uma experiência ou algo que faça o aluno manipular e ver aquilo que eu expliquei em sala de aula. Eu acho que eles (os alunos) fazendo, eles aprendem melhor do que somente eu falando para eles. Não acho um debate uma aula prática." (Professora A)

"[...] além das experiências de laboratório, as experiências do dia-a-dia. Realizo em sala de aula algumas atividades demonstrativas". (Professora D)

"Uma aula prática é aquela que não somente é realizada na sala de aula. É a pesquisa de pedimos para eles, pode ser no laboratório, em um bosque, parque, jardim, horta. Quando levamos os alunos para uma excursão, para um estudo do meio, acho que isso é uma atividade prática." (Professora E, grifo nosso)

"[...] experiências que a gente realiza em laboratório é um exemplo de atividade prática. Mas estudo do meio, excursões e demonstrações também são". (Professora $\mathrm{H}$ )

"Aula prática é você trabalhar de forma concreta. A teoria trabalho antes, dou uma analisada, eles se interam, 'faz' pesquisas. Até que o aluno, chega o momento, e o aluno põe a mão e investiga sobre aquilo que ensinei [...]. O ensino de Ciências tem que ser palpável." (Professora M, grifo nosso)

Por exemplo, a professora E esclarece que a aula prática pode ser uma pesquisa, desde que "no laboratório, no bosque, parque, jardim, horta", ou seja, onde o aluno encontre objetos presentes fisicamente que lhes possibilitem obter e interagir com dados do mundo natural. Esta professora e a professora $\mathrm{M}$ se referem ainda ao caráter de pesquisa que deve permear estas aulas, como se nota nos grifos dos trechos destacados, caráter este valorizado nos estudos sobre Ensino de Ciências.

Todas as professoras concordam que há necessidade de interação do aluno com a presença física do objeto para classificarem uma aula como aula prática, seja ela entendida como apenas aula de laboratório ou experimental, seja ela entendida de forma mais ampla. Nenhuma inclui atividades apenas teóricas, de modo que a visão das professoras é diferente da visão de estudos como os de Raboni (2002) e Barreto Filho (2001), nos quais qualquer tarefa em que o aluno esteja "ativo" é atividade prática. São aulas em que o "aluno põe a mão" (Professora M) e "conduz o experimento" (Professora I), ou manipula algo. A presença do verbo "manipular" na resposta de quatro professoras (A, B, G e J) denota o agir do aluno na consecução da aula, como nos exemplos:

"(Aulas práticas são) basicamente as aulas de laboratório. Mas algum experimento feito em sala de aula também é aula prática. Mas os alunos precisam manipular os experimentos.” (Professora B, grifo nosso) 
"[...] acredito que é a aula que o aluno participe da montagem e manipulação de um experimento". (Professora C, grifo nosso)

Em relação às atividades práticas especificamente, uma das questões pedia para as professoras indicarem oralmente com o que se preocupam ao proporem tais atividades, oferecendo as afirmativas indicadas no rodapé do Quadro 1.

Quadro 1. Principal preocupação das professoras quando usam atividades práticas, em ordem de importância das afirmações 1 a $6^{*}$.

\begin{tabular}{|c|c|}
\hline Professoras $^{*}$ & Ordem das respostas \\
\hline B & $5-6-2-1-4-3$ \\
\hline D & $5-1-2-6-4-3$ \\
\hline F & $5-6-1-2-4-3$ \\
\hline G & $5-2-6-1-3-4$ \\
\hline I & $5-1-2-6-4-3$ \\
\hline L & $5-6-1-2-4-3$ \\
\hline M & $5-1-2-6-4-3$ \\
\hline
\end{tabular}

Fonte: Sistematização dos próprios autores; afirmações: (1) despertar a curiosidade do aluno e motivá-lo; (2) preparar habilidades científicas; (3) modificar as ideias prévias dos alunos; (4) desenvolver, no aluno, a capacidade de questionar, refletir, propor hipóteses, interpretar, e, desta forma, estimular o raciocínio científico; (5) facilitar a aprendizagem da Ciência; (6) comprovar o que foi visto na aula teórica.

*O quadro não incluiu as professoras A, C, E, H e J, pois afirmaram não utilizar atividades práticas.

As professoras utilizam atividades práticas porque, em seu entender, estas facilitam a aprendizagem da Ciência, uma vez que a afirmativa 5 é citada em primeiro lugar. Em sua maioria, elas propõem estas atividades para comprovar o que foi visto na aula teórica (6) e despertar a curiosidade do aluno (1); só uma professora - professora $G$, que vem apresentando respostas mais coerentes com um ensino investigativo - refere-se, em segundo lugar, ao potencial destas aulas para preparar habilidades científicas (2). Despertar a curiosidade do aluno (1) fica sempre entre as primeiras e quartas colocações, assim como a alternativa de comprovar a aula teórica. As alternativas (3) e (4), que se referiam a uma visão defendida pelos pesquisadores, ficam sempre nas duas últimas opções. Ou seja, os professores não apresentam visão coerente com a valorizada nas pesquisas, como as abordadas por Campanário e Moya (1999) na sistematização de diversas orientações investigativas em Ensino de Ciências.

Embora revelem dar importância às atividades práticas, este tipo de atividade não é vista como oportunidade de problematização do conteúdo, mas sim de reafirmação do que foi visto. Deste modo, possivelmente, estas professoras não envolvem o estudante na investigação 
Andrade, M. L. F.; Massabni, V. G.

do conteúdo escolar, como sugerem os PCN, nem buscam, nestas atividades, formas de aprendizagem de novos conteúdos não apresentados, a priori, na aula teórica. Nota-se que esta compreensão da função da atividade prática por professoras especialistas, com licenciatura na área de Ciências, é semelhante às de professoras não especialistas do estudo de Raboni (2002). Segundo Raboni (2002, p. 38), na opinião das professoras de $1^{a}$ a $4^{a}$ séries, as atividades práticas servem para: "a) ilustrar a matéria; b) fazer com que os alunos vejam a teoria acontecendo; c) despertar a curiosidade dos alunos; d) divertir, quebrando a monotonia da aula expositiva".

Segundo Cachapuz et al. (2005), apesar da importância dada (verbalmente) à experimentação e à observação pelos professores, o ensino é livresco, sem trabalho experimental real, a não ser quando apresentado como "receitas de cozinha". Esta valorização da atividade prática pelos professores torna-se, então, relativa, como notado, também, por Raboni (2002), por ser contraditório dizerem que as valorizam e, de fato, não as utilizarem. Possivelmente, da forma como as professoras desenvolvem suas aulas, as atividades práticas se tornam apenas complemento, embora tenham a firme convicção de que não deveriam ser. Isto parece gerar um sentimento de angústia e insegurança, resgatado nas falas das professoras sobre as razões de não utilizarem atividades práticas em seu cotidiano.

\section{Razões para a não-utilização de atividades práticas no cotidiano escolar}

As professoras justificam não utilizarem atividades práticas em suas aulas, sobretudo, por causa do grande número de alunos por turma - dificuldade esta que não depende só delas para ser superada. As Professoras C, J e E salientam que não há espaço físico adequado para trabalharem com turmas numerosas em atividades práticas:

"Sinceramente não trabalho. É muito aluno em sala de aula. Cada sala tem uns 35 alunos em média. Fica impossivel trabalhar com essa quantidade." (Professora C)

"Não trabalho com atividades práticas. É muito alunos na sala de aula [...] em média 35 a 40 alunos em uma sala de aula muito pequena. Não tem espaço. A gente pede material para a direção, eles disponibilizam para nós. Além disso, é muito dificil trabalhar com alunos pequenos." (Professora J)

"Não uso porque a direção não disponibiliz̧a todo o material que necessito. Pedi uns reagentes para ensinar reação ácido-base no ano passado e até agora nada. Simplesmente não uso nestas condições!" (Professora E)

A necessidade de providenciar, com a direção, ou mesmo com os alunos, o material para as atividades práticas indica que estes materiais não estão prontamente disponíveis para a utilização e que, possivelmente, não há ou não se usa um local de armazenagem, como um laboratório. Assim, esta indisponibilidade de material e local é um fator para a não-utilização de atividades práticas. 
Ramos e Rosa (2008), também preocupados com as razões para utilização/não-utilização de atividades práticas do tipo experimental pelo professor do Ensino Fundamental, percebem que não utilizar atividades experimentais se deve, entre outros fatores: à pequena quantidade de material, à ausência de um local adequado e, mesmo, à falta de preparo do professor para lidar com este tipo de atividade. Para Barros e Hosoume (2008), a maioria das atividades experimentais escolares pode envolver o manuseio de materiais de fácil acesso, baratos e de montagem fácil. Daí é compreensível a utilização de atividades simples, com materiais caseiros, pelos professores. Porém, ao mesmo tempo em que esta é uma alternativa interessante para se superarem as dificuldades, pode colaborar para a realização de atividades práticas pedagogicamente empobrecidas e simplistas, dependendo do modo como são desenvolvidas.

Há que se compreender a ótica dos professores, de acordo com Tardif (2002). Os docentes consideram difícil gerenciar um grupo grande de alunos quando realizam atividades práticas, pois este tipo de atividade requer ao professor acompanhá-los de forma individual ou em pequenos grupos no processo de aprendizagem. Classes numerosas desfavorecem a utilização não só de atividades práticas, mas também de qualquer outra aula que saia do esquema tradicional de ensino, em que o aluno fica passivo. Iniciativas dos professores que eventualmente possam causar deslocamento e agitação dos alunos dificultam o gerenciamento da classe (GIMENO SACRISTÁN, 2000). Para Gimeno Sacristán (2000, p. 166), a atividade dos professores, por ser uma ação que ocorre dentro de uma instituição, é uma prática condicionada pelas condições e características da instituição escolar, de modo que "a ação observável é fruto da modelação que os professores realizam dentro de campos institucionais de referência".

As professoras mostram-se preocupadas com a possibilidade de ocorrerem comportamentos inadequados dos alunos em atividades práticas, especialmente as experimentais, pois, diferentemente de outras aulas, se lida com materiais que podem cair, quebrar, ferir o colega, pegar fogo, de modo que comportamentos inadequados são potencialmente perigosos para os alunos. Esta insegurança existe nos docentes, pois são cobrados pela manutenção da "ordem" em sala - tanto dos alunos quanto do local que utilizam para as atividades práticas, sem que se tenha oficialmente pessoal de apoio para auxiliar nesta organização, como um técnico de laboratório. Mesmo entre as professoras que afirmam usar atividades práticas, a insegurança em desenvolvê-las aparece, como se nota no depoimento a seguir:

"Eu uso atividade prática muito pouco. Eu sinceramente fico aflita em levar meus alunos para o laboratório. Eu tenho medo que eles quebrem alguma coisa. No laboratório eles não se concentram, faz̧em bagunça, começam um a bater no outro. É bem dificil para o professor mesmo!!! Eu já realizei algumas experiências no pátio da escola mesmo. Eu acho que deveria deixar na sala de aula a metade da sala e a outra metade iria para o laboratório. Eu já levei uma classe inteira para o laboratório, mas foi terrível." (Professora G, grifo nosso)

Quando muito, os professores que se empenham em realizar atividades práticas conseguem a colaboração camarada de outro profissional da escola, o que tende a vir com o tempo, durante o qual se estabelecem os vínculos com os outros profissionais. Esta necessidade de angariar apoio dentro da escola faz com que professores recém-ingressantes tenham uma dificuldade a mais, como afirma a Professora A: 
Andrade, M. L. F.; Massabni, V. G.

"Não trabalhei ainda, pois estou chegando agora nesta escola [...] Ainda estou conhecendo a escola [...]. Mas pretendo, após as férias de julho, preparar algumas atividades práticas para fazer algumas atividades.” (Professora A)

Sabe-se que os professores costumam trocar de escola com frequência, e toda uma rede de relações interpessoais precisa ser construída/reconstruída em cada escola que entram, para formar um ambiente favorável ao desenvolvimento das atividades práticas. Por exemplo, podem solicitar outro profissional, como o coordenador pedagógico, para ficar com metade da classe, enquanto trabalham com a outra metade, driblando, assim, as dificuldades com classes numerosas, como sugerido pela Professora G.

A falta de tempo, tanto para prepararem essas atividades antes da aula quanto para as desenvolverem durante uma aula, em apenas cinquenta minutos, também acarretam o pouco uso de atividades práticas, conforme estas professoras:

"Usei atividades práticas poucas vezes como professora. No começo, quando comecei a dar aula sim, mas depois me desmotivei. Dou em média 35 aulas por semana, e não dá tempo para preparar nada." (Professora I)

Entre as professoras, duas (B e F) utilizaram atividades práticas devido à colaboração de estagiários de Licenciatura:

"Poucas vezes. Principalmente quando tem algum estagiário tem alguma idéia e trazpara gente aplicar, dai eu faço algumas experiências.” (Professora B)

"Trabalhei pouco com atividades práticas. Trabalhei com alguns estagiários da faculdade $X^{3}$. Alguma coisa a gente fa\%, mas é pouco.” (Professora F)

Cabe ressaltar a interação da escola com a universidade, por meio dos estágios dos alunos de Licenciatura, como contribuição para a inserção de novas metodologias de ensino e incentivo à realização de atividades práticas, uma vez que esses acadêmicos podem facilitar sua implementação, pois além de produzirem/desenvolverem, com o professor, estas atividades, atuam ainda como pessoal de apoio no desenvolvimento destas aulas.

As entrevistas indicam que o uso de atividades práticas é raro, mesmo entre professoras experientes. Ter experiência no manejo da classe, na condução do ensino, no auxílio à aprendizagem dos alunos poderia ser um fator favorecedor para o desenvolvimento de atividades práticas, pois estas são dificuldades relatadas quando indagado por que não utilizam atividades práticas. Porém, ter experiência em sala de aula parece não implicar ter melhor destreza para planejar a aula e gerir a classe em atividades práticas.

${ }^{3} \mathrm{O}$ nome da faculdade foi omitido por questões éticas. 


\section{Considerações finais}

Cabe pensar em como propiciar o uso de atividades práticas no cotidiano da escola, uma vez que as professoras deste estudo raramente as utilizam. Uma primeira consideração é que os professores precisam conhecer melhor as funções investigativas que estas atividades propiciam, como indicado pelos estudos em Ensino de Ciências citados no presente artigo. Deste modo, podem modificar a visão da função das atividades práticas no ensino, entendidas basicamente como forma de exemplificar, ilustrar ou comprovar o que é visto na aula teórica, esta, sim, tida como importante. Que sejam valorizadas enquanto oportunidade de construção de conhecimento dos alunos, ampliando o potencial destas aulas no que diz respeito ao interesse despertado e a aprendizagem.

Para modificar esta visão, é necessário um preparo teórico e prático dos professores, a fim de discutirem o valor das atividades práticas e as formas de implementá-las no cotidiano. Mesmo assim, estes docentes, possivelmente, só se sentirão impelidos a implementarem estas atividades se se sentirem confiantes em desenvolvê-las de forma proveitosa na escola, com tempo para planejarem e explorarem o conteúdo "novo" que pode advir das atividades, a fim de orientarem os alunos. Esta confiança deve ser parte de um processo de formação inicial na licenciatura, em que tais atividades sejam valorizadas e o licenciando seja preparado para desenvolvê-las nas condições reais de ensino. Necessita, também, ser parte do processo de formação continuada, em que o apoio do formador ao docente em exercício efetivamente o auxilie a trabalhar na realidade da escola, não com laboratórios ideais, considerando procedentes suas dificuldades.

Pouco adiantará o bom preparo do professor se não houver todo um movimento da escola em prol da iniciativa de desenvolver atividades práticas, oferecendo condições materiais e apoio - movimento aparentemente deixado para os pesquisadores da área de Ensino de Ciências. A escola é um espaço de aprendizagem, e qualquer espaço pode ser trabalhado a fim de ser útil a uma prática que priorize a experiência direta dos estudantes, sendo este um compromisso a ser assumido pelas escolas, não só pelos docentes da área. Viabilizar trabalhos no entorno da escola, nos seus jardins, pátios, e - por que não? - nos laboratórios escolares, com a construção ou revitalização de espaços adequados a tais atividades, demonstra que a própria escola as valoriza.

Atividades práticas bem elaboradas, com discussões teóricas apropriadas, requerem dedicação, pesquisa prévia e tempo para planejamento. Assim, podem se tornar promotoras da aprendizagem, e não simplesmente um passeio ou uma "aula diferente". O sistema educacional pode apoiar estas atividades, integrando-as no cotidiano. Para isto, ações concretas são requisitadas. Sugere-se viabilizar um horário para o preparo, na escola, das atividades práticas pelos professores da área, tal como o Horário de Trabalho Pedagógico Coletivo (HTPC). Presume-se, porém, que esta medida seria pouco efetiva sem outras que garantam o vínculo do professor com uma escola apenas, para que, nesta, se forme um corpo de professores, um coletivo, e, dedicando-se à sua escola, o professor da área possa se comprometer a montar espaços para atividades práticas, como, por exemplo, revitalizar o laboratório. Isto requer alterar a remuneração e a quantidade de aulas lecionadas pelos professores de Ciências, visto que muitos se dedicam a várias escolas para completar sua jornada e seu salário, criando pouco vínculo com cada uma delas e, ainda menos, com os alunos. 
Andrade, M. L. F.; Massabni, V. G.

Quando se forma um corpo estável de professores em uma escola, há possibilidades de se investir em construções, em ideais, em projetos duráveis por mais de um ano - quando costuma haver a troca de escola por professores. Pode-se, assim, formar-se um grupo de professores de diferentes disciplinas da área - Ciências, Biologia, Química, Física -, entre outros, que se interessem em trabalhar de forma interdisciplinar. Por exemplo, um experimento que simule o efeito estufa pode ser preparado por todos os docentes do grupo e explorado em cada disciplina de forma diferente, dependendo do enfoque e profundidade de abordagem. Sem dúvida, os alunos, grandes beneficiários destas alterações, podem elaborar ações, tal como a mobilização do Grêmio Estudantil, para angariar fundos para a compra de materiais para as atividades práticas e realizar monitorias.

Assim, forma-se um espaço de estudo e discussão das atividades práticas na escola, favorecendo a busca de apoio material e financeiro junto à Direção Escolar, Diretorias de Ensino e Secretarias de Educação. Ações conjuntas são necessárias se o que se deseja é incluir as atividades práticas nas escolas, como parte de um projeto mais amplo de formação e cidadania, prevendo a execução de tais atividades explicitamente no Projeto Político Pedagógico das escolas e em políticas públicas.

Outra medida de cunho abrangente do sistema educacional seria reduzir o tamanho das turmas, fator muito citado pelos professores para não utilizarem atividades práticas. A qualidade de uma aula com atividades práticas fica comprometida quando existem muitos alunos, pois são aulas que exigem atenção redobrada dos docentes, seja para orientá-los quanto aos conhecimentos científicos que se quer trabalhar, seja para organizar e verificar o andamento da aula, de modo a evitar situações perigosas ou não favorecedoras da aprendizagem. Aumentar o valor pago por estas aulas, bem como dotar as escolas com um profissional efetivo no quadro de funcionários, seja ele um professor assistente ou técnico de laboratório, facilitaria a inclusão de tais atividades.

Finalizando, melhorias nas condições de formação e trabalho dos professores da rede pública de ensino estão intimamente associadas à possibilidade de implementação de atividades práticas nas escolas. Senão, somente professores abnegados se aventurarão na proposição destas atividades, gerando, com razão, um sentimento de frustração nos demais, estendida para o local de trabalho. Conclui-se que, se queremos melhorar a aprendizagem de Ciências, urge dar condições para o desenvolvimento de atividades práticas nas escolas, sendo, para isto, fundamental sua valorização pelo professor, valorização esta que requer perceber seu potencial para formar sujeitos que entendam e valorizem a Ciência e suas implicações no cotidiano, ideal que é favorecido quando as atividades práticas são desenvolvidas de forma investigativa. Faz-se necessário dar oportunidade para os professores de Ciências encontrarem meios para fazerem, da escola, um espaço propício à realização de atividades práticas. A construção deste espaço é, portanto, coletiva, e requer a melhoria das condições reais em que se desenvolve a prática educativa. Quando pesquisadores, dirigentes, alunos, professores e formuladores de políticas públicas valorizam tais atividades, buscam caminhos para que elas aconteçam no cotidiano da escola. 
O desenvolvimento de atividades práticas na escola: ...

\section{Referências}

ANDRADE, M. L. F. Atividades práticas: desafios no Ensino de Ciências na rede pública de ensino. 2007. Relatório de Iniciação Científica/PIBID - ESALQ, Universidade de São Paulo, Piracicaba, 2007.

ALVAREZ, M. A. Modelo de análise do papel das aulas práticas no ensino de bioquímica. 2002. 299f. Tese (Doutorado em Ciências) - Instituto de Química, Universidade de São Paulo, São Paulo, 2002.

BARRETO FILHO, B. Atividades práticas na $8^{a}$ série do Ensino Fundamental: luz numa abordagem regionalizada. 2001. 128f. Tese (Doutorado em Educação) - Faculdade de Educação, Universidade Estadual de Campinas, Campinas, 2001.

BARROS, P. R. P.; HOSOUME, Y. Um olhar sobre as atividades experimentais nos livros didáticos de Física. In: ENCONTRO DE PESQUISA EM ENSINO DE FÍSICA, 11., 2008, Curitiba. Resumos... Curitiba, 2008. Disponível em: < http:// www.sbf1.sbfisica.org.br/eventos/epef/xi/sys/resumos/T0288-2.pdf>. Acesso em: 20 fev. 2009.

BRASIL. Ministério da Educação. Secretaria de Educação Fundamental. Parâmetros Curriculares Nacionais: Ciências Naturais. 2. ed. Rio de Janeiro: DP\&A, 2000.

CACHAPUZ, A. et al. (Orgs.). A necessária renovação do ensino das ciências. São Paulo: Cortez, 2005.

CAMPANÁRIO, J. M.; MOYA, A. ¿Cómo enseñar ciencias? Principales tendencias y propuestas. Enseñanza de las Ciencias, Barcelona, v. 17, n. 2, p. 179-192, 1999.

COLL, C.; GILLIÈRON, C. Jean Piaget: o desenvolvimento da inteligência e a construção do pensamento racional. In: LEITE, L. B. (Org.). Piaget e a Escola de Genebra. São Paulo: Cortez, 1987. p. 13-50.

COQUIDÉ, M. Um olhar sobre a experimentação na escola primária francesa. Ensaio, Belo Horizonte, v. 10, n. 1, p. 1-18, 2008.

DEMCZUK, O. M.; AMORIM, M. A. L.; ROSA, R. T. N. Atividades didáticas baseadas em experimentos no ensino de botânica: o relato de uma experiência. In: ENCONTRO NACIONAL DE ENSINO DE BIOLOGIA, 1., e ENCONTRO REGIONAL DE ENSINO DE BIOLOGIA, 3., 2005, Rio de Janeiro. Anais... Rio de Janeiro: Sociedade Brasileira de Ensino de Biologia, 2005. p. 503-505.

ERN, E.; AIRES, J. A. Contribuições da história das disciplinas escolares para a história do ensino de ciências. Disponível em: < http://www.seer.ufrgs.br/index.php/ educacaoerealidade/article/viewFile/6662/3978 >. Acesso em: 20 abr. 2009.

GIMENO SACRISTÁN, J. O currículo: uma reflexão sobre a prática. 3. ed. Porto Alegre: ArtMed, 2000.

KRASILCHIK, M. Prática de ensino de biologia. 4. ed. São Paulo: EDUSP, 2004.

O professor e o currículo das ciências. São Paulo: EPU; EDUSP, 1987. 
Andrade, M. L. F.; Massabni, V. G.

KUHN, T. S. Lógica da descoberta ou psicologia da pesquisa. In: LAKATOS, I.;

MUSGRAVE, A. (Orgs.). A crítica e o desenvolvimento do conhecimento. São Paulo: Cultrix, EDUSP, 1979. p. 5-32.

MASSABNI, V. G. O construtivismo do professor: de Piaget às idéias e práticas de professores de Ciências. 2005. 268f. Tese (Doutorado em Educação Escolar) - Faculdade de Filosofia, Ciências e Letras, Universidade Estadual Paulista, Araraquara, 2005.

OLIVEIRA, M. T. M. Didáctica da biologia. Lisboa: Universidade Aberta, 1991.

PIAGET, J. Psicologia e pedagogia. Rio de Janeiro: Forense, 1972.

Psicologia e epistemologia - por uma teoria do conhecimento. 2. ed. Rio de Janeiro: Forense Universitária, 1978.

. Abstração reflexionante: relações lógico-aritméticas e ordem das relações espaciais. Porto Alegre: Artes Médicas, 1995.

RABONI, P. C. A. Atividades práticas de ciências naturais na formação de professores para as séries iniciais. 2002. 183f. Tese (Doutorado em Educação) Faculdade de Educação, Universidade Estadual de Campinas, Campinas, 2002.

RAMOS, L. B. C.; ROSA, P. R. S. O ensino de ciências: fatores intrínsecos e extrínsecos que limitam a realização de atividades experimentais pelo professor dos anos iniciais do ensino fundamental. Investigações em Ensino de Ciências, Porto Alegre, v. 13, n. 3, p. 299-331, 2008.

ROSITO, B. A. O ensino de ciências e a experimentação. In: MORAES, R. (Org).

Construtivismo e ensino de ciências: reflexões epistemológicas e metodológicas. Porto Alegre: EDIPUCRG, 2003. p. 195-208.

SOUZA, K. R. O. et al. O papel das atividades práticas-laboratoriais no ensino de genética. In: ENCONTRO NACIONAL DE ENSINO DE BIOLOGIA, 1., e ENCONTRO REGIONAL DE ENSINO DE BIOLOGIA, 3., 2005, Rio de Janeiro. Anais... Rio de Janeiro: Sociedade Brasileira de Ensino de Biologia, 2005. p. 343-346.

TARDIF, M. Saberes docentes e formação profissional. 3. ed. Petrópolis: Vozes, 2002.

ZANON, D. A. V.; FREITAS, D. A aula de ciências nas séries iniciais do ensino fundamental: ações que favorecem a sua aprendizagem. Ciências \& Cognição, Rio de Janeiro, v. 10, n. 1, p. 93-103, 2007.

Artigo recebido em 12/08/2010. Aceito em 15/03/2011. 